\title{
PESQUISA EM ENSINO DE TEXTO NA ESCOLA: AS QUALIDADES DISCURSIVAS NO EXERCÍCIO DA PRODUÇÃO E DA ANÁLISE DE TEXTOS
}

\author{
Daniela Favero Netto \\ Adauto Locatelli Taufer \\ Amelia Biesek Lovatto
}

Submetido em 13 de maio de 2019.

Aceito para publicação em 01 de agosto de 2019.

Cadernos do IL, Porto Alegre, n. ${ }^{\circ}$ 59, outubro. p. 291-306.

\section{POLÍTICA DE DIREITO AUTORAL}

Autores que publicam nesta revista concordam com os seguintes termos:

1. Os autores mantêm os direitos autorais e concedem à revista o direito de primeira publicação, com o trabalho simultaneamente licenciado sob a Creative Commons Attribution License, permitindo o compartilhamento do trabalho com reconhecimento da autoria do trabalho e publicação inicial nesta revista.

2. Os autores têm autorização para assumir contratos adicionais separadamente, para distribuição não exclusiva da versão do trabalho publicada nesta revista (ex.: publicar em repositório institucional ou como capítulo de livro), com reconhecimento de autoria e publicação inicial nesta revista.

3. Os autores têm permissão e são estimulados a publicar e distribuir seu trabalho online (ex.: em repositórios institucionais ou na sua página pessoal) a qualquer ponto antes ou durante o processo editorial, já que isso pode gerar alterações produtivas, bem como aumentar o impacto e a citação do trabalho publicado.

4. Os autores estão conscientes de que a revista não se responsabiliza pela solicitação ou pelo pagamento de direitos autorais referentes às imagens incorporadas ao artigo. A obtenção de autorização para a publicação de imagens, de autoria do próprio autor do artigo ou de terceiros, é de responsabilidade do autor. Por esta razão, para todos os artigos que contenham imagens, o autor deve ter uma autorização do uso da imagem, sem qualquer ônus financeiro para os Cadernos do IL.

POLÍTICA DE ACESSO LIVRE

Esta revista oferece acesso livre imediato ao seu conteúdo, seguindo o princípio de que disponibilizar gratuitamente o conhecimento científico ao público proporciona sua democratização.

http://seer.ufrgs.br/cadernosdoil/index

Terça-feira, 29 de outubro de 2019. 


\title{
PESQUISA EM ENSINO DE TEXTO NA ESCOPESQUISA EM ENSINO DE TEXTO NA ESCOLA: AS QUALIDADES DISCURSIVAS NO EXERCÍCIO DA PRODUÇÃO E DA ANÁLISE DE TEXTOS
}

\author{
RESEARCH ON TEACHING WRITING IN SCHOOL: \\ USING DISCURSIVE QUALITIES FOR PRODUCING \\ AND ANALYZING TEXTS
}

\author{
Daniela Favero Netto * \\ Adauto Locatelli Taufer* \\ Amelia Biesek Lovatto ${ }^{* *}$
}

\begin{abstract}
RESUMO: Este artigo apresenta um estudo que investigou por que o aluno da Educação Básica busca escrever sobre o que está distante quando há o que dizer sobre o que só ele pode contar. Para tanto, oferecemos uma disciplina, em caráter eletivo, a alunos do Ensino Médio de uma escola pública. Os textos seguiram a proposta de Guedes (2009), que utiliza qualidades discursivas no exercício da produção e da análise textuais. A metodologia de pesquisa utilizada é a pesquisa-ação. A análise aponta que uma disciplina eletiva é insuficiente para resultados relevantes à construção da subjetividade; porém foi possível assinalar aspectos importantes relacionados à produção guiada pelas qualidades discursivas e pela leitura pública.
\end{abstract}

PALAVRAS-CHAVE: relato pessoal; produção textual; Educação Básica.

ABSTRACT: This article presents a study that investigated why students write about what is distant instead of what is close to them. To investigate this hypothesis, we offered an optional discipline to High School students of a public school. The texts written followed the methodology presented by Guedes (2009), which consists in using discursive qualities for writing and analyzing texts. The methodology used in this research is action research. The results point out that the time available for the optional discipline was insufficient to have significant results in terms of subjectivity development. However, important aspects related to the writing process guided by the discursive qualities and the reading aloud practice were remarked.

KEYWORDS: personal testimony; writing; primary; secondary education.

\section{Introdução}

Este artigo resulta de um estudo que partiu de considerações apresentadas na

\footnotetext{
* Professora do Colégio de Aplicação da Universidade Federal do Rio Grande do Sul (UFRGS), doutora em Letras, na área de Estudos da Linguagem, Linguística Aplicada, pelo Programa de Pós-Graduação em Letras da UFRGS. E-mail: d.faveronetto@gmail.com.

** Professor do Colégio de Aplicação da UFRGS, doutor em Letras, em Estudos de Literaturas Brasileira, Luso-Africanas e Portuguesa, pelo Programa de Pós-Graduação em Letras da UFRGS. E-mail: adauto.taufer@gmail.com.

${ }_{* * * *}$ Licenciada em Letras pela UFRGS e mestranda na área de Estudos da Linguagem, Linguística Aplicada, do Programa de Pós-Graduação em Letras da UFRGS. E-mail: amelia.lovatto@gmail.com.
} 
tese intitulada Ensino-aprendizagem de textos argumentativos: formulando $e$ reformulando práticas de sala de aula na Educação Básica ${ }^{1}$, defendida em janeiro de 2017 (NETTO, 2017a), no Programa de Pós-Graduação em Letras da Universidade Federal do Rio Grande do Sul (PPGLET-UFRGS). A questão-problema que norteou a tese é a seguinte: qual a contribuição dos estudos de Guedes (2009) para a qualidade dos textos argumentativos de alunos do Ensino Médio, a partir do desenvolvimento das qualidades discursivas apontadas pelo autor e, como consequência desse desenvolvimento, para o reconhecimento do destinatário nas produções textuais? Entre os resultados apontados, interessou-nos, especialmente, o seguinte: a necessidade de desenvolver estratégias para que estudantes se sintam capazes de escrever para dialogar com outros textos que estão no mundo, e não apenas repetir o senso comum, o que também o professor precisa exercitar para melhor auxiliá-los.

Diante desse apontamento, fazemos, aqui, um desdobramento da pesquisa ${ }^{2}$ realizada. Para esse desdobramento, foi oferecida a disciplina "Produção textual: o depoimento pessoal como fio condutor para a organização de ideias" a alunos do terceiro ano do Ensino Médio do Colégio de Aplicação da Universidade Federal do Rio Grande do Sul (doravante CAp-UFRGS), no segundo semestre de 2017, em caráter eletivo. A disciplina ${ }^{3}$, além de possibilitar o aprimoramento das produções escritas dos alunos nela matriculados, a partir do estudo e da aplicação das qualidades discursivas propostas por Guedes, gerou os dados para a realização deste trabalho, cujo intuito é o desenvolvimento de estratégias que auxiliem os alunos na produção de conhecimento, algo igualmente necessário ao professor, o mediador nessa busca.

Para a apresentação do estudo, organizamos o artigo da seguinte forma: apontamos o problema que deu origem ao estudo e o alinhamento teórico da pesquisa; em seguida, as estratégias metodológicas para seu desenvolvimento; e, por fim, apresentamos a análise dos dados e os resultados da pesquisa.

\section{0 problema evidenciado e o percurso teórico em via de mão dupla com a prática}

Do lugar de onde falamos, entendemos a linguagem na concepção bakhtiniana, que está indissoluvelmente relacionada a um ponto de vista sócio-histórico, cultural e interacional, isto é, sua análise não pode prescindir da comunicação entre os sujeitos nela envolvidos e dos discursos produzidos na interação verbal. A interação verbal se dá por meio do enunciado, a real unidade da comunicação discursiva (BAKHTIN, 2011), o qual tem como limite a alternância de sujeitos do discurso - quando a palavra é transmitida ao outro - e tem como características a expressividade e a conclusividade. Em outras palavras, o enunciado é composto por um elemento expressivo: "a relação subjetiva emocionalmente valorativa do falante com o conteúdo do objeto e do sentido do seu enunciado" (BAKHTIN, 2011, p. 289). E sua conclusividade, por sua vez, nada mais é do que a possibilidade de responder ao enunciado por meio de um projeto de

\footnotetext{
${ }^{1}$ Da tese, resultou o livro Produção textual: formulando e reformulando práticas de sala de aula, publicado pela Paco Editorial em novembro de 2017.

${ }^{2}$ A pesquisa foi submetida à Comissão de Pesquisa do CAp (COMPESQ-CAp) para análise de mérito científico no ano de 2017. A referida Comissão não indicou submissão ao Comitê de Ética. Ainda assim, solicitamos aos participantes que assinassem Termos de Consentimento/Assentimento, conforme será retomado em 3.1.

${ }^{3}$ Ministrada por Adauto Locatelli Taufer e Amelia Biesek Lovatto.
} 
discurso, uma intenção que se realizará por meio de um gênero do discurso (BAKHTIN, 2011). Na escrita, porém, a ausência física do interlocutor impede o questionamento acerca das possíveis lacunas do texto. $\mathrm{O}$ autor, portanto, necessita preencher essas lacunas, em um árduo exercício de antecipação da compreensão responsiva do leitor.

Se essa dificuldade é inerente à prática do autor experiente, o que dizer da prática de escrita em âmbito escolar? É sobre essa lacuna e, especialmente, sobre a dificuldade de quem escreve de se colocar como protagonista de sua produção, pois é sujeito no mundo, que essa pesquisa se propõe a investigar, e é com o preenchimento desse espaço que ela pretende contribuir por meio da prática reflexiva. Esta, por sua vez, permite ao professor se ver como protagonista do seu trabalho, como um profissional capaz de se transformar, pois evidencia que ele tem ciência de que se insere em um contexto constituído histórica e socialmente, cujas amarras podem, de certa forma, prejudicar a visão que ele tem de sua própria prática.

Os textos produzidos por estudantes de Ensino Médio, ao longo da disciplina eletiva oferecida no segundo semestre de 2017 no CAp-UFRGS, foram escritos a partir de propostas que abordam essencialmente questões pessoais. Partimos do pressuposto de que é preciso organizar os conhecimentos que estão dentro de nós para, então, recorrermos ao que está fora de nós somente se for de fato necessário. A pesquisa, realizada em contexto de sala de aula, traz essa hipótese com base em uma constatação exemplificada por meio do texto ${ }^{4}$ a seguir, conforme consta na tese referida na introdução deste artigo:

Tecnologia para o mal?

A tecnologia avança cada vez mais, e avança em uma velocidade exponencial; até ontem estávamos mandando cartas para poder nos comunicar com pessoas distantes, hoje temos smartphones que fazem quase tudo: comunicação, desenhos, projetos, etc. Porém isso estava "preso" a virtual, mas as coisas vem mudando, a linha entre o virtual e o real está cada vez mais tênue.

Uma das mais instigantes e surpreendentes tecnologias que vem se popularizando talvez sejam as impressoras tridimensionais, máquinas capazes de transformar o virtual em real, concreto; Com elas se tornou possivel e, principalmente, fácil "desenhar" qualquer objeto no computador e torna-lo realidade em pouco tempo. No entanto há algumas limitações; algumas estruturas não podem ser feitas pois a impressora não é capaz de ir em todas as direções; e, atualmente, a impressão só pode ser feita utilizando o plástico como principal material. Mas isso não diminui seu potencial, seja ele para o "bem" ou para o "mal".

Há pouco tempo circulou na mídia o caso de um homem que desenhou e fabricou, em sua própria casa, uma arma utilizando uma impressora 3D. A arma era toda de plástico; porém os projéteis eram feitos de metal (provavelmente comprados). O homem foi preso e posteriormente foi constatado que a arma poderia ser letal.

Também recentemente divulgado na mídia uma reportagem sobre uma escola que utiliza uma impressora 3D para a construção de estações meteorológicas modulares (feitas com eletrônica de softwares e hardwares livres). O projeto segue em parceria com uma universidade e contempla jovens com bolsas de estudo de física e eletrônica.

Esses dois casos, além de diversos outros, ilustram os diferentes usos dessa ferramenta incrível, e como ela pode ter finalidades completamente diferentes. A impressora $3 D$ não pode ser classificada como "boa" ou "má", pois como a maioria das tecnologias, isso depende do uso que fazemos dela.

\footnotetext{
${ }^{4}$ Mantivemos a escrita original do texto do aluno. Não foram feitas por nós, portanto, quaisquer modificações em seu texto.
} 
Esse texto foi escrito por um aluno que integrava um projeto de pesquisa sobre estações meteorológicas desenvolvido no CAp-UFRGS, sob orientação do professor de Física. Os estudos realizados pelo estudante lançavam mão do trabalho com impressora 3D. Dessa forma, o autor, com conhecimento de causa, poderia discorrer sobre o assunto, afinal, utilizava o equipamento sistematicamente para fins de pesquisa.

Durante a leitura pública do texto, os demais alunos estranharam o fato de o autor desconsiderar questões referentes a um projeto de pesquisa do qual ele tinha bastante conhecimento. Em vez de aproveitar os conhecimentos adquiridos durante o processo de pesquisa, o estudante pesquisou em fontes externas ao projeto desenvolvido. Os colegas, em sua maioria, desconheciam o que eram "estações meteorológicas modulares", apontando, então, um problema com relação à concretude do parágrafo em que este termo apareceu. Quando tratou do tema, o autor exemplificou o uso da impressora como sendo um "uso da tecnologia para o bem"; ele deveria, portanto, se comprometer em deixar o significado disso tudo muito claro ao leitor, a fim de que este acreditasse no seu ponto de vista, mostrando que se tratava de fato de um exemplo de bom uso da tecnologia ${ }^{5}$.

Por que o autor buscou referência em um texto (superficial) sobre as impressoras 3D? A participação num grupo de pesquisa que investiga o uso dessa tecnologia lhe forneceria subsídios para tratar do assunto com propriedade e de forma mais interessante para os leitores, seus colegas de aula, que sabiam de sua participação no projeto. Para escrever, é preciso ter clareza sobre "o que está dentro" a ponto de tornar isso claro também para o leitor, que, diferentemente do interlocutor de um enunciado falado, não estará presente para sanar possíveis dúvidas com o autor, isto é, nas palavras de Endruweit e Nunes (2013, p. 212), "há diferença entre o grau de consciência que a fala e a escrita demandam do locutor". E por que o autor não estruturou o conhecimento daquilo que está perto, daquilo que está dentro dele, para apresentar aos seus leitores (colegas e professor)? Com relação a essa questão, as autoras afirmam:

\begin{abstract}
escrever bem significa - no senso comum, muitas vezes partilhado pela escola - escrever conforme as regras norteadoras desse texto ideal. Ideal em forma e também em conteúdo. [...]. É na escola que o aluno aprende que escrever bem seria aproximar-se de modelos pré-estabelecidos, fugindo de uma escrita reveladora de conflitos, fracassos, abandonos. Há um aprendizado de não envolvimento, de falsificação das emoções e consequentemente de não reflexão sobre a própria história. Nesse sentido, não é difícil perceber que o cerne do problema está na escola que ajudou a construir uma imagem da escrita como formalidade, resultado de um treinamento para escrever na escola e fora dela. (ENDRUWEIT; NUNES, 2013, p. 209)
\end{abstract}

$\mathrm{O}$ autor sentiu-se mais seguro para defender seu ponto de vista buscando um argumento de autoridade em uma publicação que versava sobre impressoras 3D do que apresentando elementos de sua experiência pessoal como pesquisador envolvido diretamente com o uso do equipamento.

Conforme Endruweit e Nunes (2013, p. 212),

[...] escrever não é apenas colocar as ideias no papel, que não basta seguir os esquemas, observar os gêneros, escrever corretamente e seguir as regras gramaticais para termos um texto. O que falta? Em nossa percepção, falta

\footnotetext{
${ }^{5}$ Para uma análise mais detalhada, ver Netto (2017b, p. 134).
} 
É possível afirmar que a escola contribui para a construção de uma outra ausência, que dificulta ainda mais o exercício da escrita: a ausência do eu, reconhecido como sujeito no mundo, sujeito pensante e atuante. Diante do problema evidenciado, elaborou-se a seguinte questão: a leitura pública, a discussão com os colegas e com o professor, todos inseridos na mesma esfera, juntamente com a busca das qualidades discursivas de Guedes, a partir do relato pessoal, facilitarão o exercício da escrita? A intenção da pesquisa, portanto, dita de outra forma, era verificar se o aprimoramento textual poderia ser alcançado, nesse nível de ensino, por meio das estratégias de tentar suprir a ausência inerente à escrita e, especialmente, do exercício de se falar do que está perto por meio do relato pessoal.

A nosso ver, uma prática docente adequada é o estabelecimento de relação entre os saberes constituídos e a reflexão sobre as novas realidades que podem se apresentar em um ambiente de sala de aula, bem como a proposição de alternativas que contribuam para a transformação da realidade. A prática do professor deve ser, portanto, reflexiva, isto é, ele deve relacionar seus conhecimentos teórico-práticos e, quando necessário, deve rever e reformular seus fazeres a fim de transformar a realidade da qual fazem parte professor e alunos. Ousamos afirmar, ainda, que é o exemplo dessa ação docente que dará segurança ao aluno para desafiar-se de forma autônoma continuamente.

Diferentemente do trabalho com turmas completas, contexto no qual o texto Tecnologia para o mal foi elaborado, a pesquisa sobre a qual este artigo discorre, como dito, contempla a análise de produções textuais de alunos de Ensino Médio do CApUFRGS inscritos na disciplina eletiva "Produção textual: o depoimento pessoal como o fio condutor para a organização de ideias". A eletiva faz parte de um grupo de disciplinas que podem ser escolhidas pelos estudantes. Juntamente com as disciplinas regulares, as eletivas compõem o currículo escolar no Ensino Médio na referida escola. Os alunos devem, obrigatoriamente, cursar uma disciplina eletiva por semestre; e, pelo fato de poderem optar entre diversas possibilidades que lhes são oferecidas, elas recebem este nome: disciplinas eletivas.

A tese referida na introdução apontou as contribuições das qualidades discursivas de Guedes (2009) para o aprimoramento dos textos argumentativos dos alunos do Ensino Médio, em especial no que atine ao reconhecimento do destinatário (problema que se mostrou recorrente nas produções textuais analisadas) ${ }^{6}$. Com vistas ao aprimoramento da organização do conhecimento que está perto, a partir do relato - texto de caráter narrativo -, em forma de depoimento pessoal, a intenção do trabalho em sala de aula, na nova fase da pesquisa, foi o de contribuir também com a produção de textos em que o aluno construísse conhecimento, e não apenas reproduzisse o que já foi dito.

Para além dos objetivos da pesquisa, pretendia-se a inserção dos estudantes em uma esfera real de interlocução por meio do texto, isto é, o exercício da escrita possibilitando a produção de conhecimento, com um fim diferente do mero cumprimento da tarefa escolar. O cumprimento de tarefa escolar é a terceirização de um trabalho, no sentido de que se solicita ao aluno que faça um texto dentro de um modelo que lhe permite dizer, com suas palavras, aquilo que alguém ("mais importante que ele") já falou e comprovou como verdade.

Cabe, então, ressaltar que se compreende o depoimento pessoal como uma possibilidade de se falar do conhecido: de mim e do lugar em que (con)vivo. É a

\footnotetext{
${ }^{6}$ Para uma análise mais detalhada, ver Netto (2017b).
} 
narração, portanto, o caminho para falar de mim para o outro, uma vez que narrar possibilita aos indivíduos estabelecerem elos sociais. Nesse sentido, é importante considerar que a narrativa possui função significativa: permitir que o sujeito seja ouvido a partir de suas diferenças, uma vez que a presença do outro é necessária para a construção da individualidade.

Acreditamos, portanto, que a escrita tenha como uma de suas principais funções a organização da experiência subjetiva. Já a prática da escritura de textos associada a sua leitura pública, por seu turno, possibilita ao indivíduo o exercício do olhar para si seja como produtor de sentidos, seja como mediador dos conflitos alheios, como amparador de outros sujeitos. Enfim, o contato com texto, como resposta à compreensão da subjetividade, consente os mecanismos de identificação entre leitor e interlocutor.

\title{
3 Estratégias metodológicas
}

A pesquisa insere-se no âmbito da pesquisa-ação, numa relação em via de mão dupla entre teoria e prática. A prática de sala de aula, por sua vez, teve como embasamento a proposta de Guedes (2009), por meio do estudo de suas qualidades discursivas, e o estímulo à leitura oral dos textos dos alunos

Conforme Endruweit e Nunes (2013, p. 212, grifo das autoras),

\begin{abstract}
a leitura pública do texto em sala de aula funcionaria como um nível intermediário entre a presença do interlocutor na fala e a sua ausência na escrita. No momento da leitura para os colegas, a escrita faz sentido para um número de pessoas ainda presentes, mas que não representam todos os leitores possíveis do texto. Elas podem fazer - e efetivamente fazem ponderações próprias de um ouvinte. Ou seja, estão presentes, embora simbolizem uma ausência.
\end{abstract}

$\mathrm{Na}$ condição de falante, o sujeito sempre alternará posições duais da fala, a que Dufour (2000) atribui o nome de "concha vazia", isto é, o espaço interlocutório da ausência ${ }^{8}$. Para Dufour (2000, p. 55), os pronomes "eu" e "tu" constituem-se em dois signos vazios que, não referenciais com relação à realidade,

resolvem de maneira extremamente simples um problema muito complexo, o da comunicação intersubjetiva: eles estão à disposição de todo o mundo e basta que alguém fale para que essas conchas vazias se tornem cheias.

Em relação à prática de leitura pública de textos em sala de aula, a troca de vozes discursivas é constantemente evidenciada quando se alternam os locutores, autores dos textos produzidos, com vistas ao estabelecimento de um interlocutor real, o que também é garantido por meio dessa prática.

Além da proposta de leitura pública dos textos em sala de aula, as seguintes qualidades discursivas, pontuadas por Guedes (2009), foram adotadas como recurso para o aprimoramento dos textos: unidade temática, objetividade, concretude $\mathrm{e}$ questionamento.

\footnotetext{
${ }^{7}$ Dufour toma essa expressão emprestada de Gilles Deleuze, que escreveu um artigo intitulado Como se reconhece o estruturalismo?.

${ }^{8}$ Para uma análise mais detalhada, ver Taufer (2015).
} 
A unidade temática diz respeito ao assunto escolhido para se tratar no texto, ou seja, é a qualidade que está relacionada à escolha de um (e apenas um) assunto para escrever. Ela é a qualidade considerada o ponto de partida, pois é a norteadora não só para o autor - que, ao selecionar um assunto, se torna apto a selecionar o que falar sobre esse assunto -, como também o é para o leitor, que passa a saber sobre o que vai ler de início, e assim não precisa construir sucessivas hipóteses sobre o conteúdo de que o texto vai tratar.

A objetividade, conforme Guedes (2009), é necessária para o leitor compreender o texto. Nas palavras do autor, "texto objetivo é o que dá ao leitor todos os dados necessários para o entendimento do que quer dizer a partir de uma avaliação que o autor faz sobre o conhecimento prévio que o leitor deve ter a respeito do assunto em questão" (GUEDES, 2009, p. 59).

A concretude "garante que a mensagem seja expressa com precisão para que não restem dúvidas no leitor a respeito dos sentidos e valores que o autor atribuiu aos recursos expressivos com que a constituiu" (GUEDES, 2009, p. 59-60).

Dito de outra forma, a objetividade é a qualidade que trata da seleção das informações necessárias para que o leitor consiga participar do assunto sobre o qual o texto está se propondo a discutir. Já a concretude mostra essas informações e os dados textuais de forma precisa, explicitando ao leitor e garantindo que o texto revele o que o autor quer dizer. Por exemplo, se a descrição de uma pessoa for uma informação essencial para o texto, e o autor apenas informar que ele era inteligente e esperto ou às vezes o pensamento dele era bastante complexo, pouco o leitor conseguirá saber sobre a pessoa descrita, pois se trata de abstrações e de adjetivos que podem variar de acordo com a interpretação que cada leitor fizer dos vocábulos "complexo", "esperto" e "inteligente".

O questionamento, por sua vez, é a qualidade discursiva que diz respeito à capacidade do autor de envolver o leitor com o assunto do texto, isto é, trata-se de um gancho que, de certa forma, instigará o leitor a participar do diálogo proposto pelo autor. Em outras palavras, o questionamento diz respeito ao equacionamento de um problema, proporciona ao texto espaço para o leitor participar do assunto e do problema equacionado, bem como mostra ao leitor "que ele tem muito a ver com aquilo que o texto está falando" (GUEDES, 2009, p. 60).

As qualidades discursivas e a proposta de leitura pública configuram a orientação da prática desenvolvida em aula. Os textos produzidos, em sua primeira versão e a sua reescrita, por sua vez, constituem os dados submetidos à análise interpretativa.

Alguns aspectos, de modo mais específico, caracterizam a pesquisa desenvolvida como uma pesquisa-ação, quais sejam: ela parte da prática, de problemas práticos; envolve a colaboração das pessoas; e envolve uma reflexão sistemática na ação (ESTEBAN, 2010).

Conforme Esteban (2010, p. 172),

a pesquisa-ação não é o estudo daquilo que outros fazem, mas de nossas próprias práticas. Por isso, a pesquisa-ação oferece a possibilidade de superar o binômio "teoria-prática", "educador-pesquisador". Sob essa perspectiva, a prática e a teoria encontram um espaço de diálogo comum, de forma que o prático se converte em pesquisador, pois ninguém melhor do que as pessoas envolvidas em uma realidade determinada para conhecer os problemas que precisam de solução. 
Thiollent (1992, p. 14), por sua vez, assevera que:

a pesquisa-ação é um tipo de pesquisa social com base empírica que é concebida e realizada em estreita associação com uma ação ou com a resolução de um problema coletivo e no qual os pesquisadores e os participantes representativos da situação ou do problema estão envolvidos de modo cooperativo ou participativo.

É importante destacar que a prática de sala de aula em que os dados foram gerados foi organizada da seguinte maneira: a) a proposta de texto era discutida na turma entre professores e alunos; b) o texto era elaborado, individualmente, em casa; c) na aula seguinte, o texto era lido em voz alta para toda a turma (leitura pública); d) a produção, então, era discutida com base nas qualidades discursivas de Guedes; e) após os apontamentos feitos em aula, pelos alunos e pelos professores, o texto era reescrito pelo autor e entregue em sua segunda versão; f) o texto era lido pelos professores, os quais realizavam anotações e sugestões, bem como um breve parecer do texto; g) o texto era reescrito novamente pelos alunos, individualmente, em casa; h) o texto era entregue em sua versão final aos professores, que realizavam a avaliação, com parecer, e atribuíam o conceito final ${ }^{9}$. Aqui, devido ao debate oriundo da leitura pública dos textos produzidos pelos estudantes e lidos para os demais estudantes da turma e para os professores, a reversibilidade "eu-tu"/"locutor-interlocutor" ocorria a todo o instante em que os estudantes tinham a possibilidade de contribuir crítica e construtivamente para a melhoria dos textos dos colegas.

Por entendermos que a prática de leitura pública consistia num desafio para os professores e para a turma, visto que os dez estudantes inscritos na disciplina eletiva não estavam familiarizados com essa proposta pedagógica e que a disciplina eletiva duraria apenas um semestre, com uma aula de 90 minutos por semana, consideramos mais adequado não gravar as aulas. Além disso, como nosso interesse de pesquisa enfocou a qualidade das produções textuais e das participações em aula com vistas a contribuições e trocas entre estudantes-estudantes e estudantes-professores, não foram realizadas entrevistas com os participantes, mas anotações de campo referentes às participações decorrentes da prática de sala de aula.

O leitor atento identificará os professores que atuaram neste estudo como pesquisadores. Ou seriam pesquisadores que atuaram como professores? Ao apresentar uma proposta que exige do professor uma postura reflexiva e de produção de conhecimento acerca da linguagem, Geraldi (2013, p. 220) mostra "caminhos para um ensino que se assuma como uma aventura e produção de conhecimentos e não mera reprodução". Para o autor,

a aventura intelectual a que se convidam professores e alunos nada tem a ver com espontaneísmo. É possível planejar esta aventura, estabelecer objetivos bastante claros, mas fundamentalmente não é pela sistematização de conhecimentos já produzidos por outrem que se forma uma atitude de pesquisa. Mais facilmente esta sistematização produz sujeitos que repetem e não sujeitos que buscam construir seus próprios pensamentos. A busca do já produzido não faz sentido quando a reflexão que a sustenta é sonegada a

\footnotetext{
${ }^{9}$ Em aula, sempre foi ressaltado aos alunos que o conceito final não era definitivo. Se eles desejassem reescrever seus textos para alterar o conceito, com vistas à otimização de seu desempenho, estariam livres para fazê-lo.
} 
quem aprende. Esta busca deve ser resultado de perguntas e de reflexões, e não de mero conhecimento do conhecido. (GERALDI, 2013, p. 220)

Destacamos, portanto, que, no contexto descrito na pesquisa realizada, o papel do professor-pesquisador é indissolúvel. Ressaltamos que Esteban (2010) aponta como característica importante da pesquisa-ação o seu caráter interpretativo, seja por meio da análise da descrição realizada, da relação entre os achados e uma teoria ou, ainda, pela aproximação do pesquisador com a experiência particular.

\subsection{Descrição do corpus}

Os textos (depoimentos pessoais) que constituem o corpus da pesquisa foram produzidos pelos dez alunos inscritos na disciplina eletiva "Produção textual: o depoimento pessoal como fio condutor para a organização de ideias", elaborados sempre em três versões: a primeira versão; a reescrita a partir da leitura pública; e a segunda reescrita, a versão final, a partir da leitura individual e pareceres dos professores. Os dados gerados, portanto, consistem exclusivamente em textos produzidos pelos estudantes inscritos na disciplina eletiva e em anotações de campo realizadas pelos professores envolvidos.

Para analisar os textos para fins de pesquisa, além do diálogo inicial realizado em sala de aula acerca dos procedimentos envolvidos, foi elaborado um documento de consentimento/assentimento esclarecido, que se trata de

\footnotetext{
um código de ética desenvolvido inicialmente no campo biomédico, que surgiu a partir do questionamento a respeito da informação que deve ser passada aos pacientes diante de um possível tratamento; foi concebido para proteger práticas experimentais que pudessem violar os direitos individuais. Nas décadas de 1980 e 1990, esse conceito foi incorporado no âmbito da pesquisa social, embora alguns autores [...] questionem sua adequação e seu significado nessa área. (ESTEBAN, 2010, p. 216)
}

A disciplina eletiva teve início em agosto de 2017. Ao longo do semestre, foram realizadas produções textuais a partir das seguintes propostas: a) apresentação pessoal; b) relato sobre algum aspecto do cotidiano; c) relato de um acontecimento que resultou numa emoção forte; e d) relato de uma situação que provocou um aprendizado.

Além do objetivo de pesquisa, havia uma proposta pedagógica com enfoque no aprimoramento textual dos alunos que frequentaram a disciplina eletiva. A partir da proposta, os estudantes puderam exercitar o processo de escrita e reescrita de textos, aprimorando suas habilidades do dizer na escrita, com a oportunidade de atendimento mais individualizado em razão do número de alunos inscritos na disciplina e, principalmente, tiveram a oportunidade de realizar leitura e discussão sobre os textos com leitores reais e na própria esfera para a qual os textos foram produzidos. E é na esfera da sala de aula, na aula de Língua Portuguesa, no texto

[...] que a língua - objeto de estudos - se revela em sua totalidade quer enquanto conjunto de formas e de seu reaparecimento, quer enquanto discurso que remete a uma relação intersubjetiva constituída no próprio processo de enunciação marcada pela temporalidade e suas dimensões. (GERALDI, 2013, p. 135) 
A configuração da aula, quando se volta ao estudo do texto, desafia o professor a pensar e a repensar suas práticas em busca de que a tarefa de contribuir para $o$ aprendizado do aluno seja bem-sucedida, e, para isso, é preciso que, antes de tudo, a prática proposta faça sentido para o aluno.

\section{Análise dos dados e resultados}

Dos textos produzidos para a disciplina eletiva e que constituem os dados gerados para a pesquisa, apresentamos neste artigo a análise de uma produção e de sua segunda versão, a reescrita do texto.

A principal dificuldade assinalada pelos alunos, assim que as propostas de produção foram apresentadas, foi a falta de encontrar algo para dizer àquele grupo de leitores que "se conhecia". O ponto de chegada é o ponto de partida, isto é, o autor precisa saber aonde (em quem) quer chegar com seu texto, conduzindo o leitor não necessariamente ao mesmo lugar, mas por um caminho onde conseguirá transitar.

Essa falta de algo para dizer resulta, na maioria das vezes, na ausência das qualidades discursivas. Se o autor não sabe o que quer dizer, como pode desenvolver unidade temática em seu texto? Se não tem unidade temática, como vai equacionar um problema para convidar o leitor a pensar sobre ele? E como o autor irá selecionar dados e fatos relevantes para contar ao leitor?

Tendo essa dificuldade em vista, a dinâmica de algumas aulas, geralmente na apresentação da proposta, consistia em descobrir sobre o que escrever. Cada aluno expunha o assunto sobre o qual pretendia escrever, e os colegas e professores contribuíam para ele achar um caminho que o satisfizesse. Dos encaminhamentos de reescrita dados pela leitura pública, observamos que a contribuição mais significativa partia dos colegas, pois, entendemos, não eram vistas como avaliativas ou mandatórias, mas como, de fato, comentários construtivos. Um caso marcante é o de um estudante que tinha uma escrita rebuscada e confusa, com pouca objetividade e questionamento. Os professores faziam comentários chamando atenção para essas duas qualidades quando o aluno lia seus textos, mas o que fez com que o aluno reescrevesse seu texto completamente diferente foram os comentários de dois de seus colegas: "Sabe o que é? Eu nunca entendo o que tu fala", disse o primeiro; "Cara, tu escreve bem demais, mas sei lá... Não parece que tu escreve como a gente escreve, entende? Tu parece um cara bem mais velho que a gente nos teus textos. Vai ver que é por isso que a gente não entende bem o que tu escreve", disse o segundo colega. Esse feedback dado pelos colegas ao texto produzido pelo aluno foi bastante importante para que o autor tivesse a dimensão exata de como o seu texto havia sido entendido pelo seu público leitor real: os outros estudantes que frequentavam a disciplina eletiva, além dos professores que a ministravam. Acreditamos, portanto, que a leitura pública dos textos escritos e o posterior debate oriundo desse momento em que o texto saiu do domínio do autor e chegou à esfera pública (os colegas leitores) sejam, também, os responsáveis pelo aprimoramento dos textos produzidos por esses estudantes.

Ainda assim, para muitos alunos, a leitura pública era um desafio, tanto na condição de ouvinte quanto na condição de leitor, pois para ouvir um texto e contribuir significantemente com ele, os alunos deviam manter-se atentos. Nem sempre a turma mantinha o foco na leitura e, nesses momentos, lembrávamos aos alunos que, talvez, a 
falta de questionamento do texto era o que fizesse com que eles desfocassem. Manter a atenção dos ouvintes, portanto, também estava em jogo na hora da leitura pública.

A partir da leitura e da análise dos textos, notamos uma grande confusão de ideias e mistura de assuntos que, muitas vezes, resultavam em abstrações. Os alunos, frequentemente, lançavam mão de construções metafóricas pouco elaboradas no texto para tornar claro algo que, no entanto, ficava ainda mais obscuro a partir do uso dessa figura de linguagem. Esse apontamento remete ao que a tese que gerou a questão desta pesquisa pontuou acerca dos textos argumentativos: os alunos buscam o que está fora, mesmo quando querem falar de algo que está perto. No caso deste estudo, os alunos não buscavam argumentos, mas sim a concretude no texto narrativo e, com o intuito de ilustrar o que gostariam de dizer, recorriam a construções metafóricas (mais próximas da elaboração textual da esfera da escrita criativa, como a escritura de uma crônica ou de um conto literários, por exemplo) em vez de narrarem a sua própria história, com fatos concretos. É importante destacar que não vemos o emprego de figuras de linguagem como recurso negativo; pelo contrário. No entanto, no caso dos exercícios de escrita e reescrita nos moldes propostos, o uso de construções metafóricas malempregadas ia de encontro à concretude buscada com o objetivo de se evidenciar a realidade social mais próxima aos estudantes.

O texto a seguir faz parte da segunda proposta de produção textual da disciplina eletiva: relato de um aspecto do cotidiano. Neste texto, notamos uma espécie de ausência de algo sobre o que discorrer. Mais adiante, ficará evidente que, nas reescritas, houve uma tentativa de encontrar esse algo. Há também, neste exemplo, a ilustração da dificuldade na construção de um questionamento baseado na história narrada.

\section{Conflitos de gosto musical (primeira versão)}

Assim que entro no carro, já coloco meus fones de ouvido e escolho uma música. Aumento o volume até ouvir apenas o som da minha música. Não faço isso por mal, mas ouvir a mesma playlist de músicas de segunda a sexta no caminho para a escola é realmente cansativo. A tal rádio que o meu avô insiste em escutar, a Continental, que segundo ele tem música boa e quase não tem propaganda, nunca mudou as músicas que passam desde que sou criança, acho que não mudam desde o século passado. Não vou discordar de meu avô, as músicas são boas mesmo, mas repetidas a exaustão por essa rádio me fez enjoar de muitas.

$\mathrm{Na}$ minha adolescência, meu gosto musical digamos que evoluiu bastante. De bandas adolescentes bobas fabricadas de atores vindos do Disney Channel para boybands e girlbands fabricadas por enormes empresas de entretenimento sul coreanas, que até pouco tempo quase ninguém que não fosse tão fundo na internet assim ouviria. Não vou obrigar ninguém a ouvir o que eu gosto, vou apenas colocar os últimos lançamentos de Jay Park, BTS, Taeyang, EXO, Red Velvet e muitos outros, e vou ficar na minha enquanto sonho com o dia que os verei ao vivo e a cores.

Vou deixar meu avô escutar seus Bee Gees e relacionados da vida porque a essa altura do campeonato, ele não mudaria de gosto musical nem por decreto. Vou deixar para ouvir rádios que tocam músicas mais recentes quando eu sair com meu pai, mesmo que ele não seja um motorista tão cuidadoso assim.

Agora percebo que falta pouquíssimos dias para que eu me forme e vá todos os dias pegando ônibus para a faculdade, que é bem mais longe já que provavelmente não vou ter disciplinas no Campus do Vale, que é pertinho de casa. Então vou poder ouvir o que eu quiser no ônibus a caminho da faculdade. Talvez eu possa sentir saudade de uma ou outra música que toca nessa rádio, e também de voltar de carro nos dias de chuva. Acho que isso só vai se resolver no dia que eu tiver meu próprio carro.

Mal percebi e já estou na frente do Aplicação. Me despeço do meu avô e digo até que horas vou ficar na escola, atravessando para entrar na escola com a minha música 
tocando até eu chegar na minha sala de aula e usar a wifi para acessar o WhatsApp,

Facebook, Instagram e joguinhos.

Nessa versão do texto, a autora tenta mostrar ao leitor sua rotina de casa até a escola - o que o leitor descobre apenas ao final da leitura -, mas já é possível perceber como o texto não consegue se propor a discutir algo com o leitor. Enquanto a autora conta sua experiência musical, ela apresenta vários outros assuntos que ficam soltos, como a mudança do seu gosto musical e a troca de rotina quando ela se formar.

Outro ponto que fica solto é a relação do título com o restante do texto. O conflito ao qual o leitor é apresentado não é desenvolvido. Há uma descrição do gosto musical do avô e do gosto da autora, mas ela não explora esse conflito. Fica, portanto, a critério do leitor juntar essas partes soltas e entender o que o texto pretende dizer. $\mathrm{O}$ leitor retorna aos outros pontos soltos, que, em vez de se referirem ao conflito, a nada se relacionam, a não ser ao fluxo de pensamento da própria autora, configurando um problema com a qualidade discursiva objetividade.

Após a leitura do texto, foi apontada a necessidade de propor um questionamento. Afinal, o que a autora pretendia problematizar? Que problema ela convidava o leitor a equacionar junto dela? A nova versão do texto apresentada foi praticamente a mesma, com uma pequena alteração ao final. A quase "não reescrita" apontou para outro problema: os alunos sabem o que é reescrever?

$\mathrm{O}$ trecho alterado substitui o último parágrafo da versão anterior:

Conflitos de gosto musical (segunda versão - final alterado)

Mudar de rotina todos os dias é ao mesmo tempo emocionante e angustiante.

Encontrar outras pessoas e fazer outro caminho todos os dias é muito legal, mas por não saber como vai ser todos os dias é um pouco angustiante. Mas mudar um pouco é necessário uma hora ou outra na vida, e interessante de algum modo.

De qualquer maneira, vai se tornar uma rotina como nos dias de ensino médio, talvez mais legal ou não, mas eu só vou saber quando acontecer.

Nesse trecho adicionado em substituição do último parágrafo do texto, vemos a tentativa da autora de inserir um questionamento. Como já assinalado, os alunos parecem não ter compreendido o que constitui o trabalho da reescrita. Foi acrescentado um novo final ao texto, que não necessariamente se relaciona com a história. Como a mudança de rotina se relaciona ao gosto musical dela e do avô? Para a segunda versão reescrita do texto, dessa vez apenas lida e comentada pelos professores, foram feitos os seguintes apontamentos: a) a "bronca" (o querer dizer do texto) está apenas ao final, mas ela deve perpassar o texto inteiro; b) há que se discutir mais algumas afirmações (mudar um pouco é necessário uma hora ou outra na vida, e interessante de algum modo).

No entanto, o que é interessante de se observar nessa versão é a forma como a autora encaminha o texto da ida à escola ouvindo as músicas dela e as do avô para a mudança de rotina. Ou melhor, como ela poderia encaminhar. Por que a autora não explorou esse potencial do texto? Muito provavelmente, ela não sabia que estava direcionando sua escrita para essa reflexão quando escreveu o texto, uma vez que essa discussão começou a aparecer apenas na segunda versão e durante sua discussão após a leitura pública.

A autora desse texto, diferentemente da maioria dos alunos da disciplina, não usou metáforas mal construídas nem abstrações ou descrições avulsas não relacionadas ao assunto do texto. Lançou mão apenas de sua rotina e de suas memórias da 
experiência dentro do carro. Isso se torna um ponto positivo, pois situa o leitor sobre o lugar de onde ela está falando, conferindo credibilidade ao texto, mas ainda se percebe que o texto apresenta ausência de um ponto de chegada (ou seria de partida?).

Para a reescrita da versão final desse texto, houve novas sugestões envolvendo esses aspectos. A devolução da segunda versão, com novas sugestões, era feita ao final da aula, e envolvia também uma conversa com aqueles que tivessem dúvidas, o que era possível em razão de a turma ser composta por somente dez estudantes. Alguns alunos traziam seus textos e suas dificuldades para os professores, que procuravam ajudar na resolução dos problemas enfrentados. A entrega das reescritas e a devolução com comentários, diferentemente da leitura pública, eram realizadas em níveis mais individualizados com os alunos.

$\mathrm{Na}$ versão final desse texto, há um resultado pouco satisfatório em relação aos apontamentos anteriores, evidenciando-se o problema da "reescrita que não existe". Nesse sentido, a aluna apenas altera o que lhe foi sugerido, sem verdadeiramente expor o questionamento no texto e discuti-lo. Aliás, é importante destacar que as alterações realizadas se constituem apenas de novas frases permeadas pelo senso comum.

\section{Conflitos de gosto musical (versão final)}

A tal rádio que o meu avô insiste em escutar, a Continental, que segundo ele tem música boa e quase não tem propaganda, nunca mudou as músicas que passam desde que sou criança, acho que não mudam desde o século passado. Não vou discordar de meu avô, as músicas são boas mesmo, mas repetidas a exaustão por essa rádio me fez enjoar de muitas. Então, assim que entro no carro, já coloco meus fones de ouvido e escolho uma música. Aumento o volume até ouvir apenas o som da minha música. Não faço isso por mal, mas ouvir a mesma playlist de músicas de segunda a sexta no caminho para a escola é realmente cansativo.

$\mathrm{Na}$ minha adolescência, meu gosto musical digamos que evoluiu bastante. De bandas adolescentes bobas fabricadas de atores vindos do Disney Channel para boybands e girlsbands fabricadas por enormes empresas de entretenimento sul coreanas, que até pouco tempo quase ninguém que não fosse tão fundo na internet assim ouviria. Não vou obrigar ninguém a ouvir o que eu gosto, vou apenas colocar os últimos lançamentos de Red Velvet, 2ne1, F(x) Twice, BIG BANG, BTS e muitos outros, e vou ficar na minha enquanto sonho com o dia que os verei ao vivo e a cores.

Vou deixar meu avô escutar seus Bee Gees e relacionados da vida porque a essa altura do campeonato, ele não mudaria de gosto musical nem por decreto. Vou deixar para ouvir rádios que tocam músicas mais recentes quando eu sair com meu pai, mesmo que ele não seja um motorista tão cuidadoso assim.

Agora percebo que falta pouquíssimos dias para que eu me forme e vá todos os dias pegando ônibus para a faculdade, que é bem mais longe já que provavelmente não vou ter disciplinas no Campus do Vale, que é pertinho de casa. Então vou poder ouvir o que eu quiser no ônibus a caminho da faculdade. Talvez eu possa sentir saudade de uma ou outra música que toca nessa rádio, e também de voltar de carro nos dias de chuva. Acho que isso só vai se resolver no dia que eu tiver meu próprio carro.

Mudar de rotina todos os dias é ao mesmo tempo emocionante e angustiante. Encontrar outras pessoas e fazer outro caminho todos os dias é muito legal, mas por não saber como vai ser todos os dias é um pouco angustiante. Mas mudar um pouco é necessário uma hora ou outra na vida, e interessante de algum modo. Não podemos viver a vida toda em uma mesma rotina, embora rotina seja rotina, um dia tudo sempre muda.

Novamente, ao final do texto, há as palavras angustiante, emocionante, legal e interessante carecendo de exemplificação, da qualidade discursiva concretude, para desfazer o caráter abstrato das descrições que contêm esses vocábulos. Por exemplo, se, em vez de a autora escrever Mudar de rotina todos os dias é ao mesmo tempo 
emocionante e angustiante, ela escrevesse Mudar de rotina todos os dias é ao mesmo tempo uma experiência tão emocionante quanto praticar bungee jumping e tão angustiante quanto estar presa a um engarrafamento, o caráter abstrato dos vocábulos emocionante e angustiante teriam compreensões mais concretas. Esse exercício também foi o que se buscou ao longo do andamento da disciplina eletiva. O senso comum presente no texto da autora pôde ser visto na adoção da expressão mudar faz bem, por exemplo. O leitor chega ao final da leitura do texto com a mesma pergunta feita na primeira versão: e o que eu, leitor, tenho a ver com essa história?

A estudante não conseguiu fazer com que o leitor se identificasse com o seu texto, ou seja, a qualidade discursiva questionamento foi pouco ou quase nada desenvolvida. No entanto, parece que ela começa a compreender que talvez a questão desse texto não seja o conflito entre gostos musicais, mas a incerteza do futuro, a experiência iminente no curso de graduação. A angústia por vislumbrar a mudança da rotina que ela vem cumprindo há anos, simbolizada pela trilha sonora que a incomoda, mas que a conforta pela segurança e a certeza de que ela tocará todos os dias por escolha do avô que a leva para a escola, parece se revelar como a problematização desse texto. Este é o papel do exercício de escrever e reescrever: organizar aquilo que ainda está bagunçado lá dentro do autor e construir esse sentido na relação dialógica estabelecida pelo texto.

\section{Considerações finais}

A disciplina eletiva, com relação ao propósito da pesquisa, mostrou-se como uma oportunidade curta de espaço para aprimoramento textual por meio das qualidades discursivas. O exercício de falar sobre o que está perto deve ser permanente na escola, isto é, encontros semanais, ao longo de seis meses, ao final do Ensino Médio, não dão conta de desconstruir as amarras da instrumentalidade da escrita construídas pela escola $^{10}$ para darem lugar à construção da subjetividade. No entanto, os resultados apontam que é um exercício possível e necessário, que deve ser proposto desde os primeiros contatos com o aprendizado de texto e do reconhecimento dos gêneros por meio dos quais a interação verbal acontece. Ainda, simultaneamente a essa interação, que se dá por meio do enunciado, é preciso que a escola permita que o estudante se reconheça como sujeito do mundo, no mundo, como protagonista.

Além disso, essas considerações abrem espaço para novas discussões acerca do ensino da escrita na escola, especialmente sobre o espaço dedicado ao relato pessoal e à narração. Encontramos, nas reescritas dos estudantes, a tentativa de correção, como se os apontamentos para o exercício da reescrita fossem erros, e não caminhos, possibilidades. As dificuldades identificadas nas produções são indícios da falta do exercício de reflexão sobre texto: o que é uma narração? Do que se trata a reescrita? Por fim, esta pesquisa chama atenção, sobretudo, para a importância de continuarmos

\footnotetext{
${ }^{10}$ Essas amarras são reforçadas, muitas vezes, pelos engessados conteúdos que os professores precisam ensinar com vistas à promoção de um ensino que seja utilitário e que tenha uma aplicabilidade imediata relacionada à produção escrita exigida pelos exames de vestibulares e pelo ENEM. Além disso, tais amarras igualmente são garantidas porque muitos professores, dependendo da linha pedagógica adotada pelas escolas em que trabalham, precisam contemplar rigorosamente os conteúdos previstos nas matrizes curriculares presentes nos livros didáticos que alicerçam seu trabalho. Por isso, também, a construção da subjetividade nas práticas de produção de texto, na escola, por vezes, é pouco contemplada.
} 
pensando caminhos para o ensino da escrita na Educação Básica, reflexão que está longe de ser esgotada.

\section{REFERÊNCIAS}

BAKHTIN, Mikail. Estética da criação verbal. 6. ed. São Paulo: Martins Fontes, 2011.

DUFOUR, Dany Robert. Os mistérios da trindade. Rio de Janeiro: Companhia de Freud, 2000.

ENDRUWEIT, Magali Lopes; NUNES, Paula Avila. O ensino da escrita visto pela ótica enunciativa: é possível ensinar uma ausência? Calidoscópio, v. 11, n. 2, p. 204213, maio/ago. 2013.

ESTEBAN, Maria Paz Sandin. Pesquisa qualitativa em educação. São Paulo: AMGH, 2010.

GERALDI, João Wanderley. Portos de passagem. 5. ed. São Paulo: WMF Martins Fontes, 2013.

GUEDES, Paulo Coimbra. Da redação à produção textual: o ensino da escrita. São Paulo: Parábola, 2009.

NETTO, Daniela Favero. Ensino-aprendizagem de textos argumentativos: formulando e reformulando práticas de sala de aula na educação básica. Tese (Doutorado em Letras) Programa de Pós-Graduação em Letras, Universidade Federal do Rio Grande do Sul, Porto Alegre, 2017a.

NETTO, Daniela Favero. Produção textual: formulando e reformulando práticas de sala de aula. Jundiaí: Paco Editorial, 2017 b.

TAUFER, Adauto Locatelli. Narrativas enjauladas: literariedade, testemunho e vivência - escrita confessional, processos de ficcionalização e modos de inserção do sujeito no discurso. Saarbrücken: Novas Edições Acadêmicas, 2015.

THIOLLENT, Michel. Metodologia da pesquisa-ação. 5. ed. São Paulo: Autores Associados, 1992. 